\title{
BMJ Open Accessibility and quality of drug company disclosures of payments to healthcare professionals and organisations in 37 countries: a European policy review
}

\author{
Piotr Ozieranski (i) , ${ }^{1}$ Luc Martinon, ${ }^{2}$ Pierre-Alain Jachiet, $^{2}$ Shai Mulinari ${ }^{3}$
}

To cite: Ozieranski $P$, Martinon L, Jachiet P-A, et al. Accessibility and quality of drug company disclosures of payments to healthcare professionals and organisations in 37 countries: a European policy review. BMJ Open 2021;11:e053138. doi:10.1136/ bmjopen-2021-053138

- Prepublication history and additional supplemental material for this paper are available online. To view these files, please visit the journal online (http://dx.doi.org/10.1136/ bmjopen-2021-053138)

Received 05 May 2021 Accepted 07 November 2021

Check for updates

(C) Author(s) (or their employer(s)) 2021. Re-use permitted under CC BY.

Published by BMJ.

${ }^{1}$ Department of Social and Policy Sciences, Centre for the Analysis of Social Policy, University of Bath, Bath, UK

${ }^{2}$ Euros for Docs, Paris, France ${ }^{3}$ Department of Sociology, Lunds Universitet, Lund, Sweden

Correspondence to

Dr Piotr Ozieranski;

p.ozieranski@bath.ac.uk

\section{ABSTRACT}

Objectives To examine the accessibility and quality of drug company payment data in Europe.

Design Comparative policy review of payment data in countries with different regulatory approaches to disclosure.

Setting 37 European countries.

Participants European Federation of Pharmaceutical Industries and Associations, its trade group and their drug company members; eurosfordocs.eu, an independent database integrating payments disclosed by companies and trade groups; regulatory bodies overseeing payment disclosure.

Main outcome measures Regulatory approaches to disclosure (self-regulation, public regulation, combination of the two); data accessibility (format, structure, searchability, customisable summary statistics, downloadability) and quality (spectrum of disclosed characteristics, payment aggregation, inclusion of taxes, recipient or donor identifiers).

Results 0 30 countries with self-regulation, five had centralised databases, with Disclosure UK displaying the highest accessibility and quality. In 23 of the remaining countries with self-regulation and available data, disclosures were published in the portable document format (PDF) on individual company websites, preventing the public from understanding payment patterns. Eurosfordocs.eu had greater accessibility than any industry-run database, but the match between the value of payments integrated in eurosfordocs.eu and summarised separately by industry in seven countries ranged between $56 \%$ and $100 \%$ depending on country. Eurosfordocs.eu shared quality shortcomings with the underlying industry data, including ambiguities in identifying payments and their recipients. Public regulation was found in 15 countries, used either alone (3), in combination (4) or in parallel with (8) self-regulation. Of these countries, 13 established centralised databases with widely ranging accessibility and quality, and sharing some shortcomings with the industry-run databases. The French database, Transparence Santé, had the highest accessibility and quality, exceeding that of Disclosure UK.

Conclusions The accessibility and quality of payment data disclosed in European countries are typically low, hindering investigation of financial conflicts of interest.
Strengths and limitations of this study

- We investigate the quality and accessibility of drug company payment disclosure data in 37 European countries.

- We use a set of measures relevant for countries with industry self-regulation, public regulation and a combination of the two.

- We present our results as a 'heat map', showing the least and most problematic aspects of payment data accessibility and quality.

- One key limitation is that that we did not quantify some aspects of the accessibility and quality of payment data.

Some improvements are straightforward but reaching the standards characterising the widely researched US Open Payments database requires major regulatory change.

\section{INTRODUCTION}

Financial conflicts of interest (FCOIs) can bias healthcare research, practice, education and policy. ${ }^{1-3}$ The last decade has seen a global trend towards addressing concerns about FCOIs by publishing drug company payments to the healthcare sector. ${ }^{4-8}$ It is best exemplified by the US Sunshine Act establishing Open Payments, a database triggering extensive research on payment distribution, ${ }^{910}$ and its links with drug prescription ${ }^{11}$ and cost. ${ }^{12} 13$ Open Payments increases transparency of FCOIs by enabling cross-checking information collected by professional organisations, ${ }^{14}$ conference organisers ${ }^{15}$ and scientific journals. ${ }^{16}$ It also aids identifying corruption by highlighting unusual payment patterns. ${ }^{1718}$

Unlike the USA, in most European countries, drug company payments are disclosed via industry self-regulation. ${ }^{46}$ In Europe, the prevalent form of self-regulation draws on 
the Code of Practice of the European Federation of Pharmaceutical Industries and Associations (EFPIA), with its minimum requirements transposed into the codes of EFPIA's national trade group members. ${ }^{19}$ Self-regulation allows the industry to develop, implement, and oversee the rules of payment disclosure. ${ }^{40}$ Compared with the US Sunshine Act, one key shortcoming of self-regulation, resulting from the industry's interpretation of European privacy laws, is making company disclosures conditional on consent granted by payment recipients. ${ }^{21-23}$ Other problems include broader, and therefore difficult to interpret, payment categories (grants and donations, contributions to costs of events, fees for service and consultancy), ${ }^{22}$ which are also fewer than in the USA, excluding royalties, ownership and investments. Additionally, research payments are only disclosed as lump sums per company without named recipients. ${ }^{5}{ }^{24}$ One advantage of self-regulation is a greater scope of covered healthcare professionals, including not only physicians but also nurses (to be included in the USA starting from 2022), ${ }^{25}$ pharmacists and others. ${ }^{52}$ Furthermore, self-regulation includes, like in the USA, not only hospital recipients of payments but also general practice surgeries, professional associations and other healthcare organisations. ${ }^{54}$

Only few European countries, including France, Portugal and Latvia, use government regulation, principally legislation, to impose disclosure requirements for donors and recipients, including mandatory disclosure. ${ }^{46}$ Finally, one country, the Netherlands, has been identified as using a combination of self and public regulation, with the disclosure regulations developed with government's input, but lacking a legal basis and enforced via self-regulation. ${ }^{4}$

The scrutiny of European payment data has been limited, except for case studies of payment distribution in the UK, ${ }^{21}{ }^{24}$ Germany ${ }^{26}$ and Ireland, ${ }^{27}$ and a comparative analysis of payments shares not disclosed by recipients in the UK, Germany, Sweden, Switzerland, Italy, Ireland and Spain. ${ }^{28}$ However, France is the sole country where relationships between payments and prescribing have been investigated. ${ }^{29}$ Similarly, the potential for detecting organisational-level FCOIs is unrealised, with only two studies examining discrepancies in payments reported separately by companies and some healthcare providers $^{30}$ and commissioners ${ }^{31}$ in England. Furthermore, corrupt relationships identified via official investigations pertaining to Greece, ${ }^{32}$ Poland and Russia ${ }^{33}$ might have been revealed earlier by examining payment patterns, following the US' example. ${ }^{17} 18$ Therefore, the evidence base for any policy reform is thin, leaving the industry as the only stakeholder likely to have in-depth understanding of payment data, particularly in countries with self-regulation.

The likely reasons behind the scant disclosure research are the low accessibility and quality of payment data. Regarding accessibility, a study of European disclosure approaches has found that of six countries with self-regulation five lacked centralised payment databases. ${ }^{4}$ In one of these countries,
Germany, the dispersal of disclosures on drug company websites was a major obstacle in data analysis. ${ }^{192628}$ A recent remedial initiative by activist data scientists has involved creating a database called eurosfordocs.eu. Inspired by a similar German project, ${ }^{26}$ eurosfordocs.eu integrates data disclosed separately by many companies in several countries with self-regulation. ${ }^{28}{ }^{34}$ Contrastingly, of the four countries identified as having government regulation or combining it with self-regulation three had databases integrating payments reported by all companies. ${ }^{4}$

A related aspect of low accessibility both in countries with self-regulation and government regulation is poor user interface. ${ }^{4}$ Of the six studied countries with self-regulation only Disclosure UK, the database run by the Association of the British Pharmaceutical Industry (ABPI), was judged as user friendly. ${ }^{4}$ However, of the three databases in countries using government regulation or combining it with self-regulation the Dutch and Portuguese databases were described as 'partially' user friendly, while the French was deemed 'not' user friendly. ${ }^{4}$ Challenges in the interface of the French database were only addressed by the independent data platform eurosfordocs.fr, stimulating journalistic investigations into FCOIs. ${ }^{35-37}$

The second problem, payment data quality, has only been examined in countries with self-regulation. For example, analyses of Disclosure UK revealed inconsistencies in reporting of payment values and recipients, ${ }^{21}{ }^{24}$ compounded by the absence of unique recipient identifiers. ${ }^{38}$ Similar shortcomings, including duplicate entries, were found in Germany, ${ }^{26}$ indicating that they might characterise self-regulation more broadly.

Therefore, important gaps exist in our understanding of the accessibility and quality of European payment data. First, ongoing debates on the introduction of public regulation in some countries ${ }^{5}$ suggest that the only comprehensive European regulatory overview ${ }^{6}$ might have missed key regulatory developments, potentially with implications for data accessibility and quality.

Second, the implementation of the requirements of the EFPIA Code ${ }^{19}$ has not been fully scrutinised. For example, although some trade groups will only meet the minimum standards (eg, by expecting companies to publish data on their websites), others might exceed them (eg, by creating centralised databases). ${ }^{42}$ The need for establishing a comprehensive pattern of compliance is underscored by findings from Sweden and the UK, suggesting failure of self-regulation of drug marketing to meet some of its own key promises. ${ }^{20} 39$

Third, regulatory approaches in many European countries have escaped scrutiny, ${ }^{4}$ making it unclear whether payment data reported in these countries share the strengths and weaknesses identified elsewhere. Consequently, although some aspects of government regulation, such as a greater scope of covered industries, have been demonstrated as superior to self-regulation, ${ }^{4}{ }^{6}$ it remains uncertain whether this is reflected by payment data accessibility or quality. ${ }^{4}$ 
Finally, the to-date evaluative criteria need refinement, as some, such as 'user friendliness', have attracted a contrasting appraisal of the same disclosure database by different expert commentators. ${ }^{42}$

We have two objectives. First, to identify regulatory approaches to payment disclosure in Europe. Second, to examine the accessibility and quality of payment data disclosed in countries with different approaches to disclosure.

\section{METHODS}

\section{Data collection}

Identification of regulatory approaches

To identify regulatory approaches to payment disclosure in Europe, PO and LM identified available peer-reviewed English-language research on the regulation of drug company payment disclosure. We searched Scopus using the terms 'Sunshine Act', 'Open Payments', as well as 'European Federation of Pharmaceutical Industries and Associations' and 'EFPIA', combined with 'disclosure'. We applied the same terms in the Google search engine to identify 'grey literature', including non-peer-reviewed reports.

Subsequently, PO and LM conducted iterative searches on websites dedicated to industry payment disclosure, including EFPIA's website and its national trade group members' websites. We also examined the country profiles published by MediSpend ${ }^{40}$ and the websites of four major companies with presence across Europe (Amgen, GSK, Merck Serono, and Bayer), providing access to company disclosure methodologies, which reflect local regulatory requirements. Finally, we considered the websites of public or multistakeholder bodies which the previous steps identified as involved in overseeing payment disclosure.

Finally, PO surveyed industry trade groups and public or multistakeholder bodies overseeing payment disclosure (online supplemental file 1 ). The first round of standardised questions was emailed in mid-November 2020, followed up by reminder messages in late December 2020 , asking recipients to provide answers by the end of the first week of January 2021. Of 34 approached pharmaceutical trade groups, 17 replied. Of those, 14 answered at least some of the questions, while the remaining ones sent holding messages. Of 13 approached public or multistakeholder bodies, 10 replied. Of those, six answered at least some of the questions, three sent holding messages and one redirected us to another institution (online supplemental file 2).

\section{Data on accessibility and quality of payment disclosures}

First, in countries with self-regulation, we considered industry codes, reports, press releases, trade group websites, and industry-run databases. Second, LM and P-AJ recorded their observations regarding the format and structure of payment data when designing scripts for scraping company and trade group websites to be integrated in eurosfordocs.eu. ${ }^{28}$ Third, in countries with disclosure overseen by public or multistakeholder bodies, the data included relevant legislation, the websites of bodies managing payment disclosure and disclosure databases. Fourth, in both countries with self-regulation and public regulation, we considered responses from our stakeholder survey. Finally, in countries with self-regulation and covered by eurosfordocs.eu, we collected-for verification purposes-national-level summary statistics published by EFPIA, industry trade groups and survey responses from the trade groups.

\section{Data analysis}

Content analysis

Most of the source material was available in English. If this was not the case, we used Google Translate and Deepl. com, clarifying any linguistic issues by cross-checking with other online sources and consulting with relevant national bodies and colleagues with language expertise.

We coded the regulatory approaches deductively, building on an earlier categorisation which distinguished countries with self-regulation, government regulation and a combination of the two. ${ }^{4}$ We modified it by considering new regulatory developments, such as the 2016 decision by the Spanish Data Protection Agency, ${ }^{41}$ making disclosure by healthcare professionals compulsory without new government regulation. ${ }^{28}$ Therefore, we replaced the 'government regulation' category with 'public regulation', comprising 'government regulation', that is, legislation relating directly to payment disclosure and 'regulatory intervention', that is, decisions by data protection agencies clarifying the rules of payment disclosure based on other existing legislation.

Deductive codes relating to data accessibility and quality were developed using earlier research. ${ }^{4}{ }^{24}$ Inductive coding was applied to the types of disclosed information and company techniques of decreasing data accessibility, which were identified when integrating industry data within eurosfordocs.eu.

The data were coded by PO and results were validated by team discussions, resolving any differences by agreement. In analysing industry-self regulation, we set the characteristics of disclosed data against recommendations from the EFPIA Code. Similar comparison was not necessary in relation to public regulation as it does not introduce any optionality.

\section{Descriptive statistical analysis}

As eurosfordocs.eu involved data extraction using disclosures published by individual companies and industry trade groups, we estimated the match between the database and the underlying data by comparing the value of payments calculated in specific countries using eurosfordocs.eu with national-level summaries obtained from industry sources.

\section{Outcome measures}

We had one primary outcome measure identifying the regulatory approaches to payment disclosure in each 
country-self-regulation, public regulation and a combination of the two. As we identified both self-regulation and public regulation in some countries, we noted the number of regulatory approaches in each country—single (only self-regulation, public regulation or a combination of the two) or two (self-regulation and public regulation used in parallel).

In countries with self-regulation, we recorded whether it was based on the EFPIA Code, including shared payment, donor and recipient categories, or involved a distinct national industry code. For countries following the EFPIA Code, we specified whether trade groups were obliged to do so as EFPIA members or did this voluntarily as non-members.

Considering countries with public regulation, we distinguished those using government regulation, regulatory intervention or both. In countries with government regulation, we distinguished those introducing bespoke legislation focusing on payment disclosure or incorporating new provisions into existing pharmaceutical or medical device legislation. In countries where public and selfregulation were used in parallel, we recorded whether any overlap existed between the donors, recipients and payments covered by each approach.

In countries combining self- and public regulation, we denoted the form of both self-regulation and public regulation and how they were integrated.

The measures of accessibility and quality reflected the heterogeneity of payment data presentation. The basic measure of accessibility applied in all countries was whether it was disclosed on a centralised database or multiple websites. In addition, for countries with centralised databases, we created a 'heat map' aiding data synthesis and interpretation (table 1).

On top of the measures included in table 1, we had one additional measure of quality for eurosfordocs.eu as a database derived from payment disclosures published by drug companies and industry trade groups. We estimated the comprehensiveness of data extraction by comparing the value of payments available in eurosfordocs.eu with those reported separately in national-level industry data summaries. We set three arbitrary levels of match-exact (no difference between eurosfordocs.eu and summary industry data), close (difference between eursofrdocs. eu and industry data worth less than $10 \%$ of summary industry data) and low (difference exceeding $10 \%$ of summary industry data).

Finally, in countries with self-regulation but without centralised databases, we examined whether industry trade groups created gateways leading to disclosure documents, as recommended by EFPIA. ${ }^{19}$ To illustrate challenges in data accessibility, we also generated lists of examples of, first, deviations from the EFPIA-recommended data presentation format ('EFPIA disclosure template') ${ }^{19}$ and, second, the ways of presenting data, which decreased its accessibility.

\section{Patient and public involvement}

We did not involve patient groups or the public. Our policy recommendations seek to increase public engagement with payment data by enhancing its accessibility and quality.

\section{RESULTS}

We first map the regulatory approaches to payment disclosure in Europe. We then examine the accessibility and quality of payment data published by pharmaceutical companies and trade groups in countries with selfregulation. Subsequently, we focus on industry data in the subset of countries with self-regulation and covered by eurosfordocs.eu. Finally, we analyse payment data in countries with public regulation or combining public regulation with industry self-regulation.

\section{Mapping European regulatory approaches to payment disclosure}

Before analysing the accessibility and quality of industry payment data, we must describe how it is disclosed in each European country (table 2).

We identified self-regulation in 30 countries in the form of codes of practice issued and overseen by industry trade groups. ${ }^{19}$ In 28 of those, the industry codes incorporate the provisions of the EFPIA Code ${ }^{194}$ as a necessary requirement of trade groups membership in EFPIA. This makes self-regulation, the 'default approach' to payment disclosure in Europe, with EFPIA holding power to exempt certain countries from following its Code. ${ }^{43}$ The first exception is Luxembourg. While the Luxembourgish trade group is not an EFPIA member, it decides voluntarily to implement the regulation of payment disclosure modelled on the EFPIA Code. ${ }^{44}$ The second exception is Denmark. Although the Danish trade group is an EFPIA member, EFPIA exempts Denmark from following its Code, given the country's separate public regulation provisions. ${ }^{43}$ As the public regulation of payment disclosure in Denmark covers only healthcare professionals, ${ }^{45}$ the Danish pharmaceutical trade group developed an additional code of practice covering only 'grants and donations' to hospitals. ${ }^{46}$

We found public regulation in 11 countries. In all cases, it takes the form of government regulation, in which provisions relating to payment disclosure are included either in bespoke new legislation (France, Lithuania and Romania) or are incorporated into existing pharmaceutical legislation (the remaining countries). In addition, in Greece, the Data Protection Agency made a regulatory intervention by issuing an interpretation of the government regulation. ${ }^{47}$

Only in France, Portugal and Turkey public regulation is the sole regulatory approach, replacing self-regulation entirely. EFPIA excepted France and Portugal from applying the EFPIA Code considering the nature of their public regulation ${ }^{43}$; however, the implementation of the 
Table 1 Heat map of measures of accessibility and quality of payment databases

\title{
Measures of payment data accessibility
}

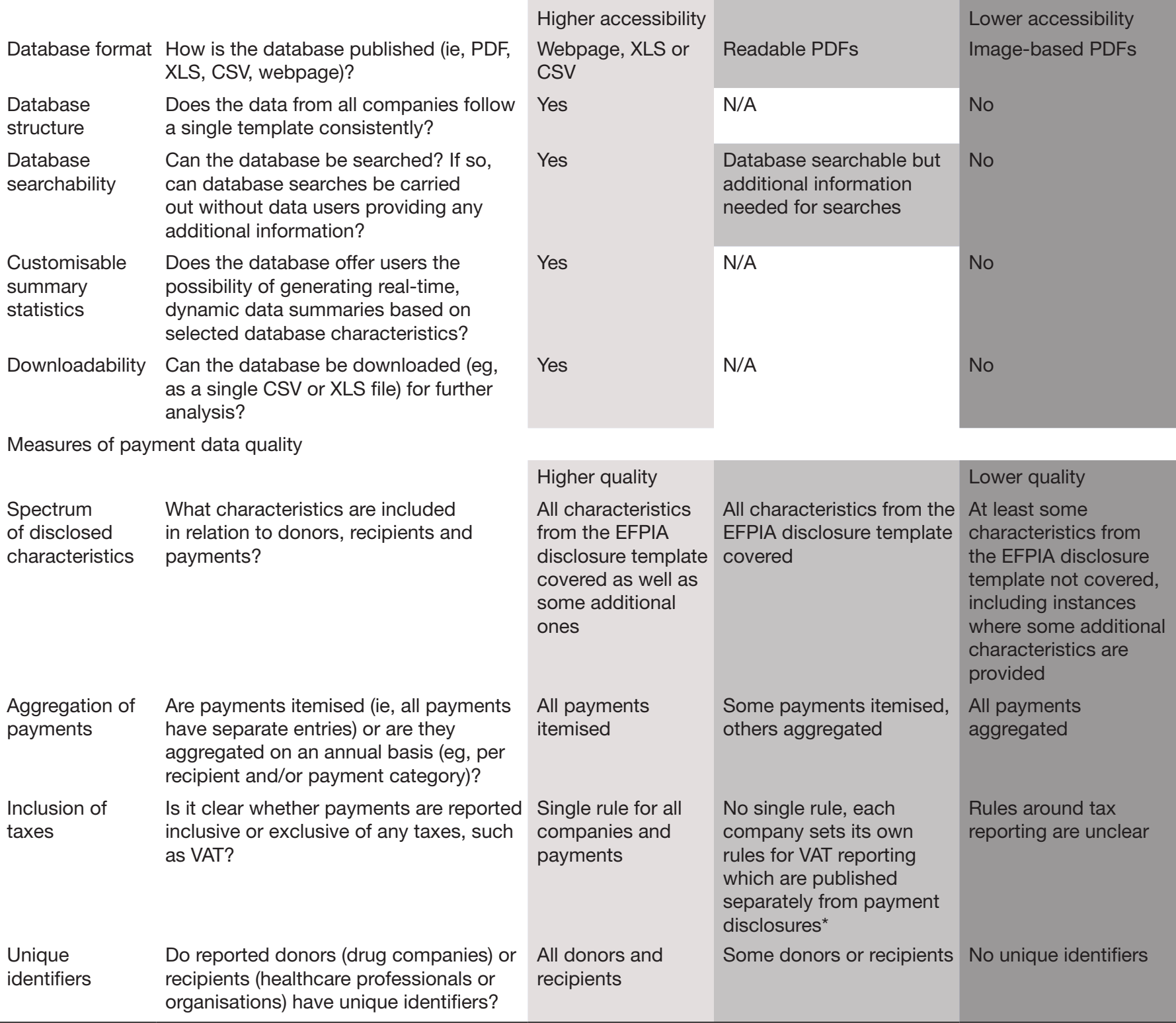

\begin{abstract}
*The EFPIA Code stipulates that companies must publish documents, called 'methodological notes', which should explain their approach to reporting VAT and other taxes. Companies publish these documents separately from payment disclosures but consulting them is necessary to understand, compare and aggregate payment values.

CSV, comma-separated values files ; EFPIA, European Federation of Pharmaceutical Industries and Associations; PDF, portable document format; VAT, Value-Added Tax; XLS, spreadsheet file format used in Microsoft Excel.
\end{abstract}

EFPIA Code in Turkey is only suspended while its compatibility with the EFPIA Code is being reviewed. ${ }^{48}$

In the remaining eight countries with public regulation, there is also parallel self-regulation. In four of these (Denmark, Lithuania, Romania and Slovakia), self and public regulations cover different donors, payments or recipients, whereas in the remaining ones (Estonia, Greece, Hungary and Latvia), donors, recipients and payments disclosed via public and self-regulation may overlap. Consequently, the existence of parallel self and public regulation in the eight countries means that self-regulation is used exclusively in 22 of the 30 countries with this approach.

Self- and public regulation are combined as a single approach in four countries. Contrasting with countries with public regulation, here, the industry contributes to managing payment disclosure. However, unlike in countries with self-regulation, the industry derives at least some of its regulatory power from public authorities, often sharing it with other stakeholders. In two of the four countries, public regulation takes the form of government regulation (Belgium and Finland), and, in 
Table 2 Approaches to regulating payment disclosure in European countries

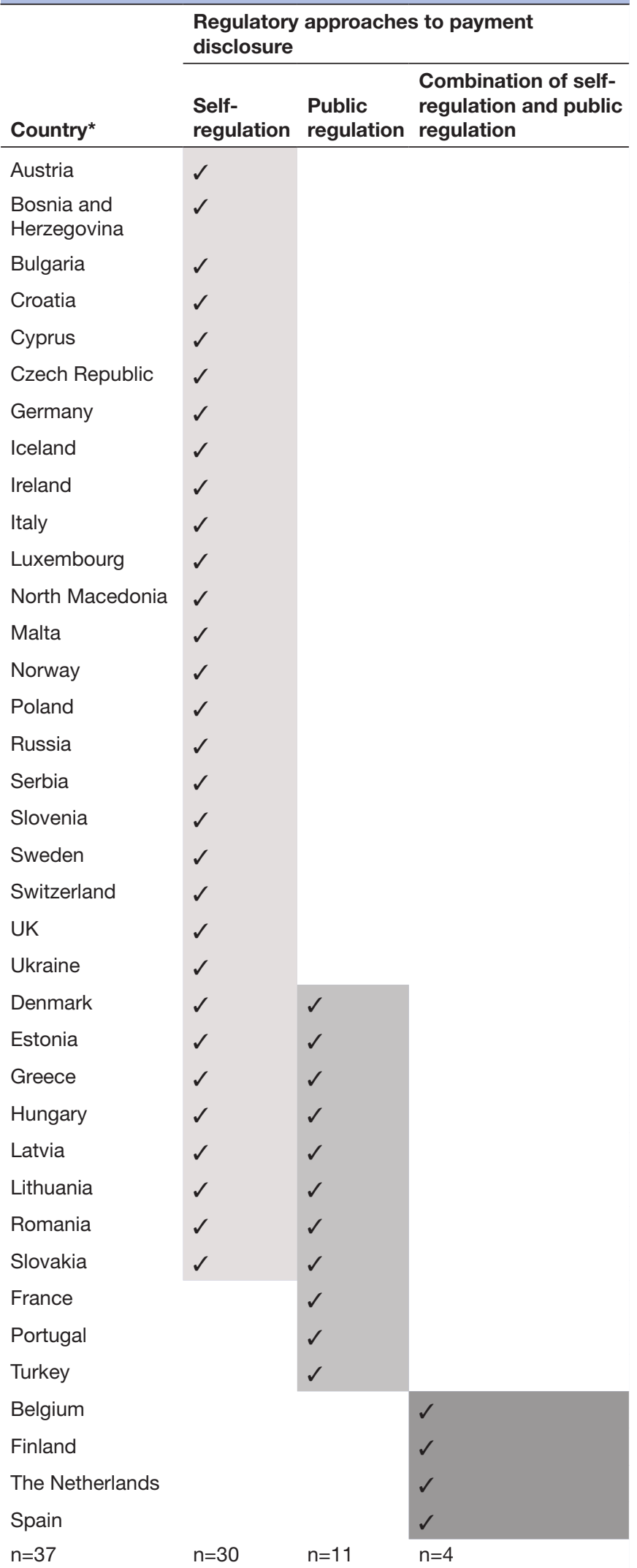

*Excluded countries: Albania, Andorra, Belarus, Lichtenstein, Monaco, Montenegro, San Marino and Vatican City. the two others-regulatory intervention (Spain and the Netherlands).

Belgium regulates payment disclosure via a bespoke 'Sunshine Act', but the interpretation of its key provisions is left to betransparent.be, a multistakeholder body involving industry and professional organisations, ${ }^{49}{ }^{50}$ which also runs the Transparency Register integrating company disclosures. ${ }^{51}{ }^{52}$ In Finland, new provisions have been introduced into the Medicines Act, stipulating that drug companies 'must keep available for public review' a list of all payments to 'associations in the fields of medicine and healthcare, ${ }^{53}$ but, in practice, the disclosure takes place following the EFPIA Code.

In Spain, public regulation involves an intervention by the Data Protection Authority, ${ }^{41}$ confirming that the publication of named payment recipients does not require recipient consent. ${ }^{28}$ However, like in Belgium and Finland, disclosure is managed by companies based on the EFPIA Code. In the Netherlands, payments are disclosed using self-regulatory rules developed by the Foundation for the Code for Pharmaceutical Advertising, which are separate from the EFPIA Code. Like in Belgium, the central platform is a multistakeholder body involving, in this case, the industry and healthcare providers. ${ }^{54}$ However, public authorities triggered the policy debate on payment disclosure and, having considered self-regulation preferable to public regulation, they lent it financial support and monitor its performance. ${ }^{55}$ Furthermore, consistent with the regulatory intervention in Spain, the Dutch Data Protection Authority confirmed that recipient consent is not required for payment disclosure. ${ }^{56}$

\section{Data disclosed via self-regulation by pharmaceutical companies and trade groups}

We were able to collect information on accessibility and quality of payment data in 28 of the 30 countries with self-regulation.

Regarding data accessibility, the EFPIA Code allows companies within each country to disclose payments either on a centralised platform or individual websites. ${ }^{19}$ However, only five trade groups have established databases for all companies, including four countries following the EFPIA Code and one using its own code (Danish Association of the Pharmaceutical Industry, LIF). Of the five industry-run databases, none had customisable summary statistics (table 3). Moreover, only one was fully searchable (ie, without additional information required for searches) and just two were downloadable. Overall, Disclosure UK had by far the highest data accessibility.

Turning to data quality, only the Czech database used unique donor and recipient identifiers consistently, but, because they were required for searches, they paradoxically decreased data accessibility. The second most frequent problem across the databases was tax reporting. While in the four databases established under the EFPIA Code, the rules on tax reporting might be reconstructed using 'methodological notes' published separately by each company, ${ }^{19}$ the Danish database had no information 


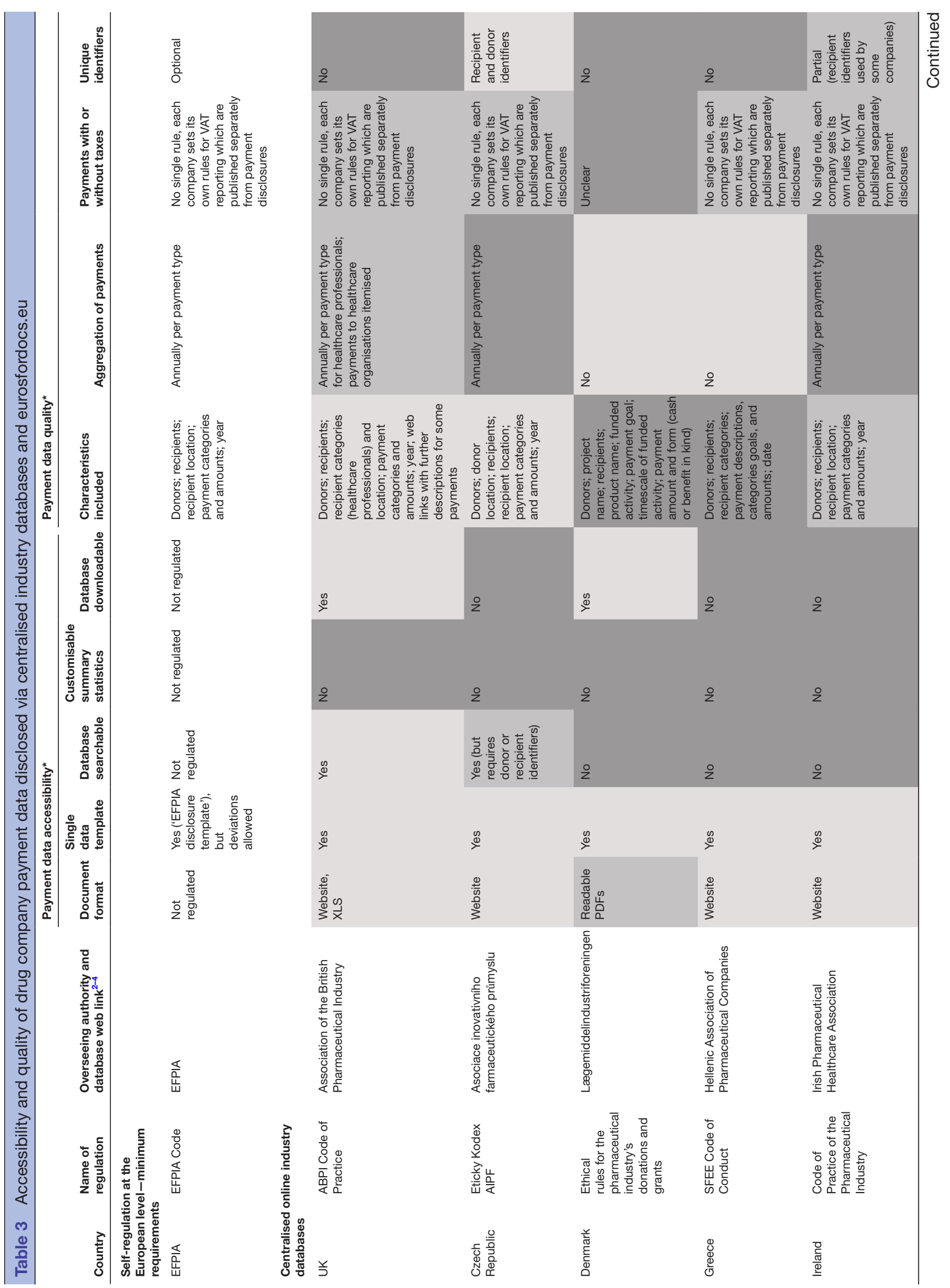


regarding tax. Taken altogether, Disclosure UK had the highest data quality, although here it was more closely matched by the Czech database.

In 23 of the remaining countries with self-regulation and available data, disclosures were published on individual websites for each company. Of these, in 18 countries, trade groups had the EFPIA-recommended gateways to these websites. ${ }^{19}{ }^{23}$ Nevertheless, without EFPIA's explicit guidance on the electronic format of disclosure documents, disclosures published on company websites in countries with and without gateways were typically PDFs. While some of these documents were 'readable', allowing for copying and pasting of information, they offered limited possibilities for efficient searches and integrating data from different companies. Additionally, some companies presented data without strictly following the 'EFPIA disclosure template', ${ }^{19}$ which further impeded possibilities for cross-company comparisons (online supplemental file 3 has examples of these deviations). Some firms apparently manipulated data presentation using low-resolution, image-based PDFs, which prevented any searches (online supplemental file 4 summarises these techniques).

Given the low accessibility of payment data, analysing its quality was practically impossible in countries without centralised databases. Therefore, we do this using eurosfordocs.eu, a database covering drug company disclosures in countries with self-regulation (Ireland, Italy, Germany, Sweden, Switzerland and the UK); in this part of the analysis, we also include Spain, a country with a combination of self- and public regulation, as it helps illustrate problems characteristic of self-regulation.

\section{Industry data disclosed via self-regulation and integrated within eurosfordocs.eu}

As already demonstrated in the previous section, Eurosfordocs.eu had data accessibility superior to all industry-run databases (table 3). While the Irish and UK databases were also searchable, eurosfordocs.eu offered customisable queries using combinations of donor and recipient names and payment categories. ${ }^{57}$ It was the only database offering customisable summary statistics enhancing data exploration. In addition, only eursofordos.eu and Disclosure UK were downloadable for further analysis.

A specific consideration regarding data integrated within eurosfordocs.eu is estimating how closely they match the underlying industry disclosures (table 4). Complete data extraction was only possible in the UK and Ireland, the two countries with centralised trade group databases (online supplemental file 5 summarises the data extraction statistics). Elsewhere, data scraping prioritised the 20 largest donors known from the countries with complete data; more data were scraped whenever allowed by formats used by companies. ${ }^{28}$ For four of the six countries, the resulting data set closely or exactly matched the industry's summary country-level data. The two countries with a low match were Germany and Spain, 
Table 4 Estimation of the comprehensiveness of industry payment data extracted for eurosfordocs.eu (2019)

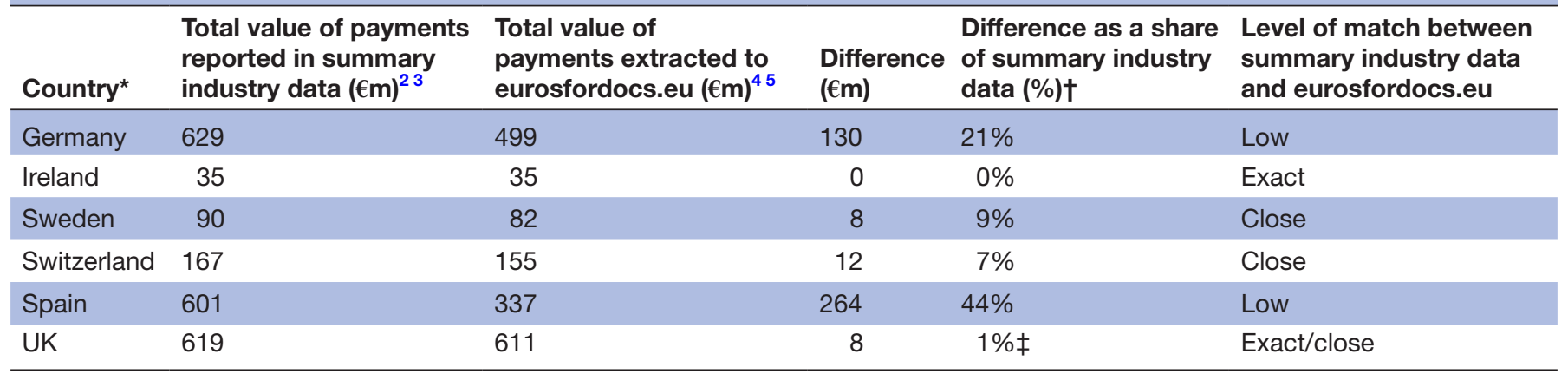

${ }^{*}$ Only countries covered by both eurosfordocs.eu and available national-level summary data generated by industry trade groups are included.

†Some of the difference between the value of payments based on summary industry data and extracted to eurosfordocs.eu results from the differences in the exchange rates. This is exemplified by the examples of Ireland (both values in euro, no difference) and the UK (original values in the sterling, the difference is caused by different exchange rates used to convert the sterling to euro). By contrast, the $1 \%$ difference between eurosfordoscs.eu and Disclosure UK results from two marginally different exchange rates used to convert the sterling to euros.

$\ddagger$ All payment values in non-euro currencies were converted to euros based on the exchange rate obtained from the CurrencyConverter, ${ }^{85}$ a Python library for exchange rates.

§Sources of national-level summary payment data. (a) Germany, ${ }^{86}$ Spain, ${ }^{87}$ Switzerland ${ }^{88}$ - publicly available pharmaceutical industry summary data published by the pharmaceutical industry trade groups. (b) Ireland-a combination of an Europe-wide report published by EFPIA ${ }^{89}$ and email communication with the Irish pharmaceutical industry trade group. ${ }^{90}$ (c) Sweden-email communication with the pharmaceutical industry trade group. (d)The UK-calculations based on data obtained from Disclosure UK, the centralised database of industry payments run by the Association of the British Pharmaceutical Industry. ${ }^{91}$

१All payment values in non-euro currencies were converted to euros based on the average yearly exchanged rates published by the European Central Bank.

${ }^{\star \star}$ The source of payment values reported in this column are centralised pharmaceutical industry payment databases (Ireland and the UK) and payment reports covering payments made by individual companies (Germany, Spain, Sweden and Switzerland).

given a high proportion of image-based PDFs hindering data extraction. ${ }^{28}$

Nevertheless, other aspects of the data quality in eurosfordocs.eu share key limitations with the underlying company disclosures.

First is a narrow spectrum of reported recipient, donor and payment characteristics. Eurosfordocs.eu does not present payment distribution within the healthcare system due to the incoherent use or omission of recipient categories by drug companies. Of all countries covered by eurosfordocs.eu, the UK is the only one where the industry trade group categorised healthcare professionals receiving payments, ${ }^{58}$ although incoherently ${ }^{21}$; healthcare organisations were nowhere categorised.

Second, consistent with the EFPIA Code ${ }^{19}$ payments to healthcare professionals are not itemised but aggregated annually per recipient within each payment category. The same applies to payments to healthcare organisations, except for the UK, where the ABPI mandates that payments to healthcare organisations be itemised. ${ }^{58}$ This UK-specific rule might explain the large difference in the number of payments reported with Germany, a country with a similar overall value of payments (online supplemental file 5). However, it is equally possible that not all companies in the remaining six countries covered by the database aggregate payments consistently as some list more than one payment per recipient, which might also indicate that although these recipients have the same names, they are different entities.
Third, the reported payment values must be interpreted cautiously as it is unclear whether they include taxes without consulting the separately published 'methodological notes' ${ }^{19}$ Some companies have different approaches to tax reporting depending on payment or recipient categories. Consequently, establishing the value of payments made by each company requires additional forensic work. ${ }^{24}$

Finally, while EFPIA introduces the option of unique recipient identifiers in disclosed payment data, ${ }^{19}$ of the seven countries covered by eurosfordocs.eu only the Spanish trade group followed this recommendation. Elsewhere the number of recipients per company and, consequently, the value of payments per recipient remains unknown. Given inconsistent naming approaches in disclosures made by the same or different companies, the same recipient can have different names, and, conversely, different recipients may have the same name. ${ }^{24}$ Furthermore, the same recipient can be identified at different levels of aggregation (eg, hospital wards, departments or hospitals), with self-regulation at least in some countries placing the onus of identifying possible multiple records on payment recipients and not companies. ${ }^{2459}$ Finally, without identifiers, payment data cannot be connected to other databases.

\section{Data disclosed via public regulation or a combination of public and self-regulation}

Having examined countries with self-regulation, we proceed to those with public regulation or a combination of public and self-regulation. 
Of the 15 countries with public regulation or a combination of self-and public regulation, all but two had centralised databases. The exceptions were Finland and Spain, where disclosures were made on individual drug company websites, consistent with the EFPIA Code. Of the 13 countries with centralised databases, one had a database, which was not publicly available (Turkey) and two others had separate databases for different payment categories (Denmark) and healthcare professionals and organisations (Greece). As the information included in the separate Danish and Greek databases, it did not differ according to our outcome measures, we consider them jointly (table 5).

The databases established via public regulation or a combination of public and self-regulation had the pattern of accessibility similar to the industry-run databases. Of the 13 databases, none had customisable summary statistics, and only 6 were downloadable and fully searchable. Overall, Transparence Santé was the frontrunner.

The most frequent data quality shortcoming was unclear tax reporting, with only two databases providing relevant rules. However, over half of the databases had at least partial donor or recipient identifiers, which was the most frequent problem in the industry-run databases. Furthermore, just five databases covered a spectrum of donor or recipient characteristics exceeding the minimum recommendations from the EFPIA Code. Transparence Santé again had the highest overall data quality.

In sum, Transparence Santé had combined data accessibility and quality exceeding that of Disclosure UK, the frontrunner industry database.

\section{DISCUSSION}

Our policy review suggests that payment data disclosure does not automatically increase transparency of financial relationships between drug companies and the healthcare sector. ${ }^{45}$ Consistently with research on disclosure of aspects of health policymaking by both public and private-sector actors, we find that achieving 'practical' or 'actionable' transparency is no less important than introducing transparency rules themselves. ${ }^{60-62}$

Although EFPIA calls payment data generated via self-regulation 'open to public scrutiny', 63 establishing the entanglement of any recipient, let alone a systemlevel picture, is impossible given the dispersal of disclosures on company websites in most European countries. Additionally, documents published as PDFs, sometimes in ways suggesting deliberate attempts to impede user engagement, fall below the Australian industry-endorsed regulations, requiring firms to use an analysable format. ${ }^{5}$ Therefore, self-regulation cannot address 'the issues of perceived conflict of interest', ${ }^{64}$ as promised by EFPIA. More broadly, the evidence of some companies and trade groups meeting only the minimum requirements from the EFPIA Code, or fulfilling them in ways inconsistent with the Code's spirit, reflects the limited success of selfregulation in modifying corporate behaviour in areas of public health policy such as reduction of sugar content in food ${ }^{65}$ or managing viewers' exposure to alcohol advertising. ${ }^{66}$

EFPIA is clearly aware of at least some of the problems in payment data accessibility. For example, in 2019, it listed 'improv(ing) access' via '[c]reateing platforms with [a] searchable tool' as one of the 'main topics' to be considered by EFPIA itself and its member trade groups. ${ }^{23}$ However, little evidence exists of subsequent discussions on this issue except for a planned 'feasibility study' of possible 'options for improving the disclosure' to be considered from 2021 to $2023 .{ }^{67}$ Furthermore, EFPIA does not seem to have recognised or engaged with the issues of low payment data quality.

Against this background, eurosfordocs.eu radically enhances data accessibility in countries without centralised industry databases, also enabling comparative investigations of country payment patterns, ${ }^{28}$ which is important given the accelerating EU-wide health initiatives. ${ }^{68}$ Although the customisable opportunities for data exploration are new to the public, data analytic firms have offered them as a consultancy service to drug companies. ${ }^{40} 69$ Consequently, eurosfordocs.eu may contribute to changing what may be the de-facto status of payment data as a commodity used to monitor internal compliance with disclosure requirements and potentially inform marketing strategies targeting healthcare professionals. ${ }^{70}$

In countries with self-regulation, the challenges in data accessibility and quality are exacerbated by nondisclosed payments. EFPIA admits the problem of '[c] onsent issues in general but also by country and by specialty', ${ }^{23}$ while evidence also exists of varying consent rates between companies. ${ }^{28}$ In addition, some companies may not disclose all their payments, as suggested by instances of underreporting of payments to patient organisations, with their disclosure also regulated by the EFPIA Code but with distinct policies. ${ }^{71} 72$ Furthermore, self-regulation only covers companies and trade groups that have ratified the EFPIA Code or its transposition into country-level codes. Therefore, disclosure requirement may not extend to companies focusing on generic or over-the-counter medicines and even major manufacturers of branded prescription medicines (eg, Vertex does not follow the ABPI Code). However, some nonmember companies may choose to follow the trade group codes voluntarily. For example, the list of Disclosure UK participants exceeds ABPI membership. ${ }^{72}$ Furthermore, some companies may belong to other trade groups (eg, generic or small biotech trade groups), which, in some countries, require their members to abide by the national codes (eg, Sweden, Denmark). Problems with underreported payments may be particularly prominent in countries with parallel self and public regulation due to possible confusion relating to where payments should be reported. For example, some healthcare organisations in England underreported some of the payments they had received given their implicit or explicit expectations that the payments would be disclosed via self-regulation. ${ }^{30} 31$ 


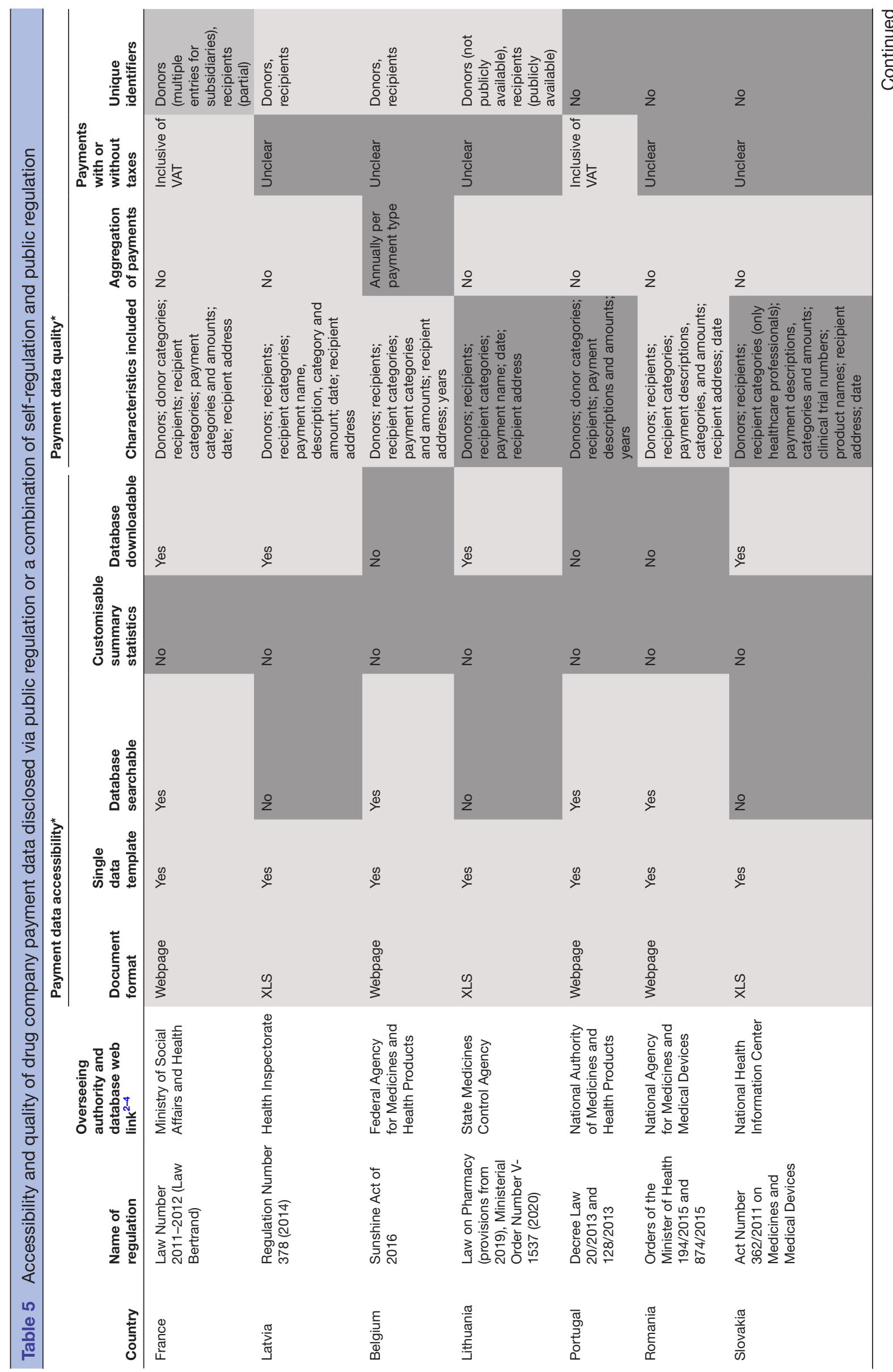



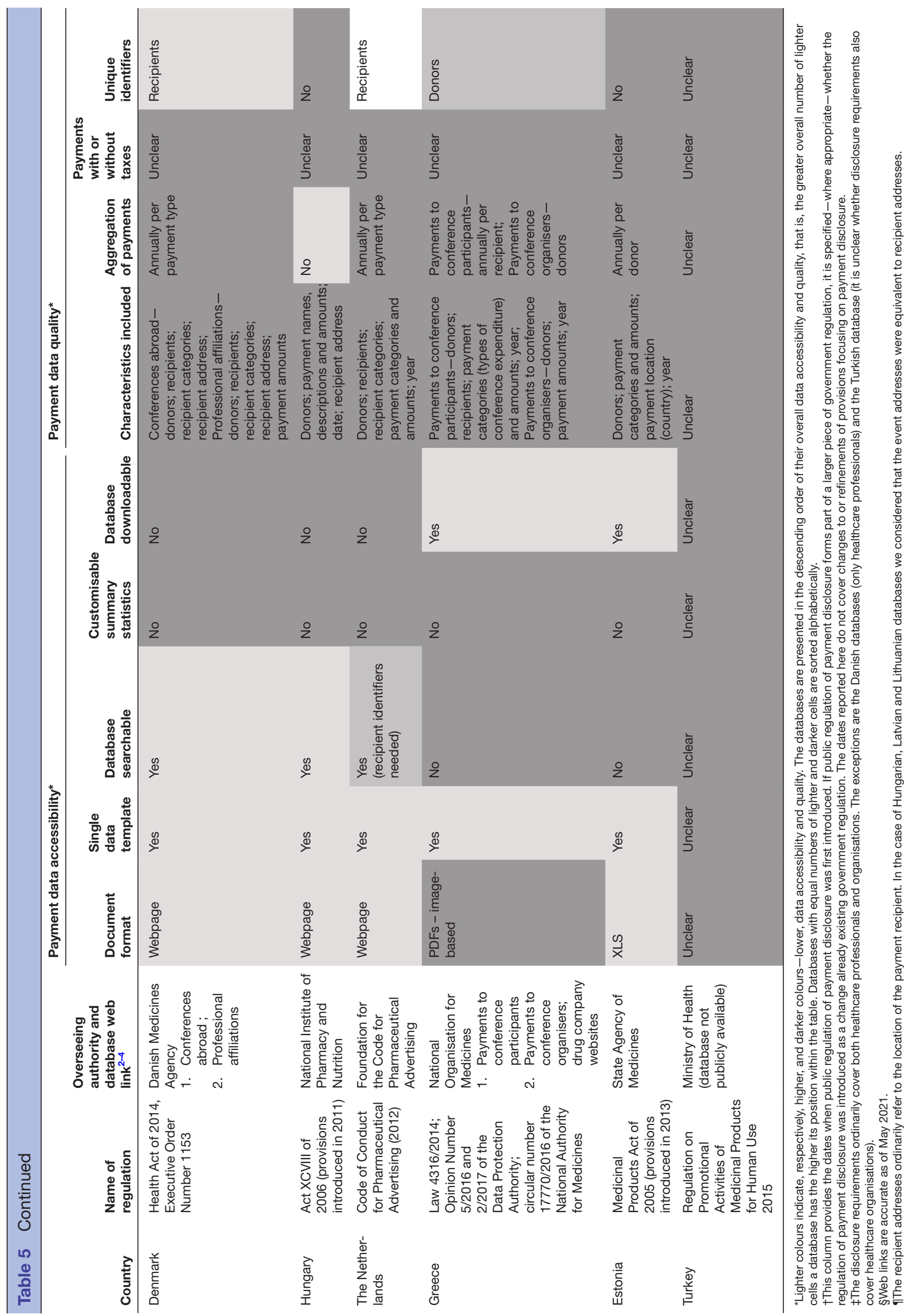
Although data reported in the US Open Payments database have attracted some criticism, ${ }^{2573}$ data accessibility and quality are vastly superior to European data disclosed using not only self-regulation but also public regulation. While the example of Transparence Santé indicates that public regulation can generate payment data outpacing industry-run databases, it often shares major shortcomings with self-regulation, including the lack of recipient identifiers or payment itemisation. ${ }^{24}{ }^{26}$ Moreover, in some databases, the spectrum of disclosed characteristics is even narrower than the minimum which EFPIA recommends for the industry. Nevertheless, public regulation eliminates optionality characterising the EFPIA Code regarding, for example, centralised databases. The legally binding nature of public regulation should also involve high levels of compliance. However, instances of inaccurate or incomplete reporting by some companies are possible. $^{25}$

Inconsistencies in the approaches to public regulation between European counties are highlighted by EFPIA and used as a key argument in favour of self-regulation, which, in EFPIA's words, represents a 'global and consistent approach for companies across Europe and common understanding for the public' ${ }^{23}$ France is one country in which problems in data accessibility and 'ergonomics' have been recognised by the Ministry of Health in 2018. ${ }^{74}$ Following this, a new version of Transparence Santé is due to be launched in late 2021 and is expected to adopt approaches to data presentation, including visualisations, similar to those developed earlier for eurosfordocs.fr. We are not aware of similar discussions in other countries with public regulation or combining self- and public regulation.

Therefore, one key area of further study would involve using qualitative methods to identify and trace relationships between the likely causes of limited corrective action seeking to address the shortcomings of the current reporting systems in European countries. Of particular importance would be examining the incentive structures and motivations of public authorities, industry trade groups and companies, healthcare professional associations as well as patient organisations at the national and EU levels.

\section{Limitations}

This study has several limitations. Our measures of data accessibility could be expanded. For example, some databases are difficult to find, including web links to the Greek and Latvian databases published within news releases, without permanent online location. Similarly, although Transparence Santé can be downloaded, the size of the data set prevents it from being opened using the standard Microsoft Excel package. Data quality could be scrutinised further by considering the types of disclosed donors, payments and recipients. ${ }^{4}$ Furthermore, qualitative insights from data users would be essential for ranking the outcome measures and attributing weights to their values, such as degrees of user friendliness.
Our focus on the database level might obscure crosscompany differences. For example, the widely ranging consent rates achieved by companies from healthcare professionals suggest that similar differences can occur in data quality and accessibility. ${ }^{21}{ }^{28}$ Furthermore, we did not calculate company-level aspects of data accessibility (eg, the share of image-based PDFs) and quality (eg, the share of duplicate entries, consistency in using donor or recipient categories and identifiers, missing data and mistakes, such as negative values). Undertaking these calculations would have necessitated extensive forensic work. ${ }^{24}$ However, these problems are likely to be widespread and serious, affecting even Transparence Santé, the database we ranked the highest based on its quality . 212426

\section{Conclusions and policy recommendations}

We formulate suggestions for enhancing public engagement with disclosed payment data (table 6), which are also relevant for non-European countries, such as Japan, experiencing problems similar to those identified in this study. ${ }^{75}$

Payment data accessibility can be enhanced with only minor revisions of the existing regulatory approaches, with the top priority being centralised databases offering possibilities for payment exploration and contextualisation.

Improving payment data quality would require new comprehensive public regulation, preferably at the European level. ${ }^{48}$ Following the example of the US Open Payments database, payments should be reported together with information on related products to allow exploring company marketing strategies. ${ }^{2476}$ Another vital piece of information to include might be the numbers of clinical trials associated with payments, as exemplified by the database run by the Slovak National Health Information Center. Furthermore, granular disclosure is vital for capturing payments of different sizes, with some US studies suggesting that even small payments impact prescribing behaviour, ${ }^{777}$ while others indicating a more complex dose-effect relationship. ${ }^{11} 297980$ Data interpretation can be enhanced by descriptions of funded activities (eg, specific conferences or projects), consistent with the EFPIA Code's requirements regarding payments to patient organisations. ${ }^{728}$ Recipient characteristics should be also expanded, reflecting how the public engages with the healthcare system. ${ }^{24}$ Finally, Open Payments highlights that recipient identifiers are necessary for reliable analysis and connecting payment data to data sets with details of prescription and procurement. ${ }^{11} 29777880$ Data integration and management require strong compliance mechanisms, including penalties for providing data of inadequate quality. ${ }^{25}$

Additionally, in European countries with self-regulation, eliminating possibilities for refusing disclosure by recipients is necessary to reduce high levels of missing data. ${ }^{28}$ The decision by the Spanish Data Protection Authority is illustrative here, exempting payment data from the provisions of the European data protection legislation (the General Data Protection Regulation, GDPR). ${ }^{28}$ 
Table 6 How can public authorities and the pharmaceutical industry improve the transparency of payment data?

\section{Recommendations for improving accessibility of payment data}

1 Create national-level databases searchable for companies, recipients and payment categories.

2 Make the databases in the CSV or XLS format for further analysis, while ensuring that the released data can be split using different variables, for example, by year or recipient type to make it manageable for users.

3 Enable users to explore the data by allowing them to generate data summaries placing payments made or received in a broader context (eg, payments made by other companies or received by the same or other recipient categories, such as medical specialty).

Recommendations for improving quality of payment data.

4 Publish unique identifiers for payment recipients shared by all companies and used consistently over time.

5 Introduce clear rules on the levels of aggregation for identifying recipients (eg, clinic, ward or hospital) to enhance the consistency of reporting.

6 Introduce categories of recipients to enable mapping the distribution of payments in the healthcare system. The categories relating to healthcare professionals could include a standardised list of medical specialties. The categories covering healthcare organisations could reflect their functions in the healthcare system as providers, commissioners or professional organisations.

7 State clearly whether reported payments should include VAT or other taxes so that payment values from different companies can be compared reliably.

8 Publish each payment individually instead of aggregating them annually per recipient.

9 Publish payment descriptions so that the public can understand the activities they fund as well as their context. This requirement would follow the self-regulatory rules existing in relation to the disclosure of payments to patient organisations.

10 Enforce and publish detail of data quality checks: eliminate missing values, payments with the value of zero and ensure that each recipient has a unique name and is reported at the same level of aggregation by all companies. Other data quality checks should involve cross-checking recipient name and address information to ensure consistency and avoid duplicate reporting.

CSV, comma-separated values files ; VAT, Value-Added tax; XLS, spreadsheet file format used in Microsoft Excel.

Finally, transparency alone cannot address FCOIs. Even the increased transparency brought in by Open Payments does not seem to have decreased physicians' acceptance of FCOIs or increased patient concerns about their possible effects on the care they receive. ${ }^{82}$ Paradoxically, transparency may normalise FCOIs or increase their impact via moral licensing. ${ }^{82}$ Therefore, transparency should be accompanied by policy measures seeking to reduce or eliminate certain FCOIs. Key European examples include banning some financial relationships, ${ }^{83}$ including payments to healthcare professionals for conference participation in Sweden ${ }^{28}$ or prohibiting sponsored meals over $€ 60$ in France. ${ }^{84}$

Acknowledgements We would like to express gratitude to all pharmaceutical industry trade groups and public authorities, which have responded to our request for information and were willing to explain the nature of local regulatory solutions. We thank, in particular, the ABPI's Disclosure UK Team for their continued interest in our research as well as professionalism and openness in sharing the fine detail of their important work. We extend our thanks to colleagues who took the time to read drafts of this paper or offer linguistic assistance: Marcell Csanadi, Eniko Csanadi, Alice Fabbri, Kevin Jean, Fatma Korkmaz, Olga Loblova, Savvas Morris, Emily Rickard, Eszter Saghy, Christos Vasilakis, and Weronika Ozieranska. We are also thankful to the BMJ Open Editors and three reviewers for their helpful and constructive comments.

Contributors $\mathrm{PO}$ is a Senior Lecturer at the Department of Social and Policy Sciences, University of Bath. PO conceived and wrote the paper, collected and analysed the data. PO is the guarantor of the paper. LM is a data scientist and the President of the Euros for Docs Association. LM created the eurosfordocs.eu database, analysed the data and contributed to writing. P-AJ formerly presided the Euros for Docs Association. P-AJ collaborated with LM on creating eurosfordocs.eu. P-AJ conceived the paper and contributed to writing. SM is an Associate Professor at the Department of Sociology, Lund University. SM conceptualised the paper and contributed to writing.
Funding This work was supported by The Swedish Research Council (VR), grant number 2020-01822 ('Following the money: cross-national study of pharmaceutical industry payments to medical associations and patient organisations').

Competing interests We have read and understood the BMJ Group policy on declaration of interests and declare the following interests: PO's PhD student was supported by a grant from Sigma Pharmaceuticals, a UK pharmacy wholesaler and distributor (not a pharmaceutical company). The PhD work funded by Sigma Pharmaceuticals is unrelated to the subject of this paper. LM and PAJ are members of Euros for Docs, a non-profit organization registered in France that seeks to promote transparency of drug company funding in the healthcare sector by making payment data accessible and complete across Europe. PAJ is employed by Haute Autorité de Santé, the French independent health technology assessment organisation. SM's partner is employed by PRA Health Sciences, a global Contract Research Organization whose custumers include many pharmaceutical companies.

Patient consent for publication Not applicable.

Ethics approval No ethical approval was needed. The ethical implications of this study article were approved via a peer ethics review process at the Department of Social and Policy Sciences, University of Bath in February 2020. This study did not require a full ethical approval as it relied on publicly available data aggregated at the organisational or country level.

Provenance and peer review Not commissioned; externally peer reviewed.

Data availability statement All data relevant to the study are included in the article or uploaded as supplementary information. We have included all relevant data as supplementary information forming part of this submission.

Supplemental material This content has been supplied by the author(s). It has not been vetted by BMJ Publishing Group Limited (BMJ) and may not have been peer-reviewed. Any opinions or recommendations discussed are solely those of the author(s) and are not endorsed by BMJ. BMJ disclaims all liability and responsibility arising from any reliance placed on the content. Where the content includes any translated material, BMJ does not warrant the accuracy and reliability of the translations (including but not limited to local regulations, clinical guidelines, terminology, drug names and drug dosages), and is not responsible for any error and/or omissions arising from translation and adaptation or otherwise.

Open access This is an open access article distributed in accordance with the Creative Commons Attribution 4.0 Unported (CC BY 4.0) license, which permits 
others to copy, redistribute, remix, transform and build upon this work for any purpose, provided the original work is properly cited, a link to the licence is given, and indication of whether changes were made. See: https://creativecommons.org/ licenses/by/4.0/

\section{ORCID iD}

Piotr Ozieranski http://orcid.org/0000-0002-2023-3288

\section{REFERENCES}

1 Lo B, Field MJ. Conflict of interest in medical research, education, and practice: national academic press, 2009. Available: https://www. nap.edu/catalog/12598/conflict-of-interest-in-medical-researcheducation-and-practice

2 Lundh A, Lexchin J, Mintzes B, et al. Industry sponsorship and research outcome. Cochrane Database Syst Rev 2017;2017.

3 Torgerson T, Wayant C, Cosgrove L, et al. Ten years later: a review of the US 2009 institute of medicine report on conflicts of interest and solutions for further reform. BMJ Evid Based Med 2020:bmjebm2020-111503.

4 Fabbri A, Santos Ala, Mezinska S, et al. Sunshine policies and murky shadows in Europe: disclosure of pharmaceutical industry payments to health professionals in nine European countries. Int $J$ Health Policy Manag 2018;7:504-9.

5 Grundy Q, Habibi R, Shnier A, et al. Decoding disclosure: comparing conflict of interest policy among the United States, France, and Australia. Health Policy 2018;122:509-18.

6 Mental Health Europe. Sunshine and transparency laws and regulations and codes across Europe, 2017. Available: https://mhesme.org/wp-content/uploads/2017/09/Mapping-of-Sunshine-Lawsin-Europe.pdf

7 Santos A. The sun shines on Europe: transparency of financial relationships in the healthcare sector, 2017

8 McDermott Will \& Emery. Snapshot of Sunshine rules in EU countries for the pharmaceutical industry, 2014. Available: https://mcdermottwill-emery-2793.docs.contently.com/v/special-report-snapshot-ofsunshine-rules-in-eu-countries-for-the-pharmaceutical-industry1

9 Moynihan R, Albarqouni L, Nangla C, et al. Financial ties between leaders of influential US professional medical associations and industry: cross sectional study. BMJ 2020;369:m1505

10 Garstka ME, Monlezun D, DuCoin C, et al. The sunshine act and surgeons: a nation-wide analysis of industry payments to physicians. J Surg Res 2019:233:41-9.

11 Yeh JS, Franklin JM, Avorn J, et al. Association of industry payments to physicians with the prescribing of brand-name statins in Massachusetts. JAMA Intern Med 2016;176:763-8.

12 Mejia J, Mejia A, Pestilli F. Open data on industry payments to healthcare providers reveal potential hidden costs to the public. Nat Commun 2019:10:4314.

13 Mitchell AP, Trivedi NU, Gennarelli RL. Are financial payments from the pharmaceutical industry associated with physician prescribing? A systematic review. Ann Intern Med 2021;174:353-61.

14 Wayant C, Walters C, Zaaza Z, et al. Evaluation of financial conflicts of interest among physician-authors of american college of rheumatology clinical practice guidelines. Arthritis Rheumatol 2020;72:1427-34.

15 Durrani I, Ji YD, Peacock ZS. Do speakers fully disclose potential conflicts of interest in oral and maxillofacial surgery? Journal of Oral and Maxillofacial Surgery 2020;78:1669-73.

16 El-Rayess H, Khamis AM, Haddad S, et al. Assessing concordance of financial conflicts of interest disclosures with payments' databases: a systematic survey of the health literature. J Clin Epidemiol 2020;127:19-28.

17 Ornstein C, Weber T, Jones RG. We found over 700 doctors who were paid more than a million dollars by drug and medical device companies 2019

18 Department of Justice - Office of Public Affairs. Medtronic to pay over \$9.2 million to Settle allegations of improper payments to South Dakota Neurosurgeon, 2020.

19 EFPIA. EFPIA Code of practice, 2019. Available: https://www.efpia. eu/relationships-code/the-efpia-code/

20 Mulinari S, Davis C, Ozieranski P. Failure of responsive regulation? pharmaceutical marketing, corporate impression management and off-label promotion of enzalutamide in Europe. $J$ White Collar Corporate Crime 2020;2631309X:097047.

21 Mulinari S, Ozieranski P. Disclosure of payments by pharmaceutical companies to healthcare professionals in the UK: analysis of the association of the British pharmaceutical industry's disclosure UK database, 2015 and 2016 cohorts. BMJ Open 2018;8:e023094.
22 Adlington K, Godlee F. Disclosure UK: transparency should no longer be an optional extra. BMJ 2016;354:i3730.

23 EFPIA. Codes committee activities report, 2019. Available: https:// www.efpia.eu/media/554642/efpia-code-report-2018.pdf

24 Ozieranski P, Csanadi M, Rickard E. Analysis of pharmaceutical industry payments to UK health care organizations in 2015. JAMA Netw Open 2019;2:e196253.

25 Adashi EY, Cohen IG. Enforcement of the physician payments sunshine act: trust and verify. JAMA 2021.

26 Stoll M, Hubenschmid L, Koch C, et al. Voluntary disclosures of payments from pharmaceutical companies to healthcare professionals in Germany: a descriptive study of disclosures in 2015 and 2016. BMJ Open 2020;10:e037395.

27 Moriarty F, Larkin J, Fahey T. Payments reported by the pharmaceutical industry in Ireland from 2015 to 2019: an observational study. Health Policy 2021;125:1297-304.

28 Mulinari S, Martinon L, Jachiet P-A, et al. Pharmaceutical industry self-regulation and non-transparency: country and company level analysis of payments to healthcare professionals in seven European countries. Health Policy 2021;125:915-22.

29 Goupil B, Balusson F, Naudet F, et al. Association between gifts from pharmaceutical companies to French general practitioners and their drug prescribing patterns in 2016: retrospective study using the French transparency in healthcare and national health data system databases. BMJ 2019;367:16015.

30 Moberly T. NHS joint working with industry is out of public sight. BMJ 2019;364:I1353.

31 Moberly T. CCGs fail to declare pharma funding. $B M$ 2018;360:j5911.

32 U.S. Attorney's Office - District of New Jersey. Novartis AG and subsidiaries to pay $\$ 345$ million to resolve foreign corrupt practices act cases, 2020. Available: https://www.justice.gov/usao-nj/pr/ novartis-ag-and-subsidiaries-pay-345-million-resolve-foreigncorrupt-practices-act-cases

33 Securities and Exchange Commission. SEC charges eli lilly and company with FCPA violations 2012, 2012. Available: https://www. sec.gov/news/press-release/2012-2012-273htm

34 Eurosfordocs.eu. Metabase, 2021. Available: https://eurosfordocs. eu/metabase/

35 Anon. Hôpitaux : les CHU ont reçu 170 millions d'euros de laboratoires pharmaceutiques en 2018, 2020. Available: https://www. lemonde.fr/sante/article/2020/01/10/hopitaux-les-chu-ont-recu170-millions-d-euros-de-laboratoires-pharmaceutiques-en-2018 6025479 1651302.html

36 Anon. Procès du Mediator: Le terreau des conflits d'intérêts l'hôpital reste fertile, 2020. Available: https://www.lemonde.fr/idees/article/ 2020/02/04/le-terreau-des-conflits-d-interets-a-I-hopital-reste-fertile 6028302_3232.html

37 Condomines A. Qu'est-ce que La plateforme EurosForDocs, qui recense les liens d'intérêts avec les industriels pharmaceutiques? 2021. Available: https://www.liberation.fr/checknews/2021/01/04/ qu-est-ce-que-la-plateforme-eurosfordocs-qui-recense-les-liens-dinterets-avec-les-industriels-pharm_1809498

38 Eaton L. Declarations of pharma funding to doctors are hit by covid-19 crisis. BMJ 2020;370:m2689.

39 Zetterqvist AV, Merlo J, Mulinari S. Complaints, complainants, and rulings regarding drug promotion in the United Kingdom and Sweden 2004-2012: a quantitative and qualitative study of pharmaceutical industry self-regulation. PLoS Med 2015;12:e1001785.

40 MediSpend. Global compliance platform 2021, 2021. Available: https://www.medispend.com/solutions/global-compliance/ [Accessed 9 Jan 2021].

41 Agencia Española de Protección de Datos. INFORME 1438818/2016 2016.

42 EFPIA. EFPIA HCP/HCO disclosure code. EFPIA code on disclosure of transfers of value from pharmaceutical companies to healthcare professionals and healthcare organisations, 2014. Available: https:// www.efpia.eu/media/25837/efpia-disclosure-code.pdf

43 Shire. EFPIA disclosure code 2018 disclosures shire pharmaceuticals, 2018. Available: https://www.takeda.com/4ab3b3/ siteassets/system/who-we-are/values-and-corporate-governance/ transparency-disclosures/efpia-disclosure-code-reports/2018/ methodology serbia english.pdf

44 APL. Code de déontologie, 2020. Available: https://www.apl-pharma lu/docs/33850f/text/2021-code-de-deontologie-apl.pdf

45 Danish Medicines Agency. Healthcare professionals having a relationship with a company, 2020. Available: https:// laegemiddelstyrelsen.dk/en/licensing/relationships/ [Accessed 17 Aug 2021].

46 Ethical Committe for the Pharmaceutical Industry. Ethical rules for the pharmaceutical industry's donations and grants (donation 
code). Available: https://www.enli.dk/media/49893/ethical-rules-ondonations-and-grants-version-20.pdf

47 Amgen. Methodological note. EFPIA \& local industry association disclosure codes 2020. Available: https://search.disclosureuk. org.uk/Public/GetMethodNoteFileForDownload?year=2019\& pharmaCompanyld=29 [Accessed 25 Feb 2020].

48 GSK. Engaging with healthcare professionals - Turkey, 2020. Available: https://www.gsk.com/en-gb/responsibility/operatingresponsibly/engaging-with-healthcare-professionals/europe/ turkey/[Accessed 18 Jan 2021].

49 betransparent.be. About us, 2020. Available: https://www. betransparent.be/en/about-us/ [Accessed 18 Jan 2020].

50 Sunshine act, 2016. Available: https://www.betransparent.be/wpcontent/uploads/2017/01/Moniteur-Belge-2016-12-27-BelgischStaatsblad.pdf

51 betransparent.be. Transparency in the interest of the patient, 2020. Available: https://www.betransparent.be/en/about-the-transparencyregister/ [Accessed 18 Jan 2020].

52 GSK. Engaging with healthcare professionals - Belgium, 2020. Available: https://www.gsk.com/en-gb/responsibility/operatingresponsibly/engaging-with-healthcare-professionals/europe/belgium/ [Accessed 18 Jan 2021].

53 Medicines act 395/1987, 1987. Available: https://www.fimea.fi/ documents/160140/765540/18580_Laakelaki_englanniksi_paivitetty_ 5 2011.pdf

54 Stichting Transparantieregister Zorg. Over het Transparantieregister, 2020. Available: https://www.transparantieregister.nl/over-het-tran sparantieregister [Accessed 18 Jan 2020].

55 Stichting Transparantieregister Zorg. Hoe werken we? 2020. Available: https://www.transparantieregister.nl/over-het-transparanti eregister/hoe-werken-we

56 Stichting Transparantieregister Zorg. Veelgestelde vragen, 2020. Available: https://www.transparantieregister.nl/veelgestelde-vragen

57 Eurosfordocs.eu. Tech documentation, 2021. Available: https:// eurosfordocs.eu/on-the-tech-side/tech-documentation/ [Accessed 9 Jan 2021].

58 ABPI. Code of practice for the pharmaceutical industry, 2019. Available: https://www.abpi.org.uk/media/6655/abpi-code-ofpractice-2019.pdf

59 ABPI. Email communication, 2021.

60 Ozierański P, Löblová O, Nicholls N, et al. Transparency in practice: evidence from 'verification analyses' issued by the Polish Agency for Health Technology Assessment in 2012-2015. Health Econ Policy Law 2019;14:182-204

61 Bullement A, Taylor M, McMordie ST, et al. Nice, in confidence: an assessment of Redaction to obscure confidential information in single technology appraisals by the National Institute for health and care excellence. Pharmacoeconomics 2019;37:1383-90.

62 Csanádi M, Ozierański P, Löblová O, et al. Shedding light on the HTA consultancy market: insights from Poland. Health Policy 2019;123:1237-43

63 EFPIA. Annual review of 2011 and outlook for 2012, 2011. Available: https://www.efpia.eu/media/25261/annual-review-of-2011-andoutlook-for-2012.pdf

64 EFPIA. Annual review of 2011 and outlook for 20122011.

65 Seferidi P, Millett C, Laverty AA. Industry self-regulation fails to deliver healthier diets, again. BMJ 2021;372:m4762.

66 Noel JK, Babor TF, Robaina K. Industry self-regulation of alcohol marketing: a systematic review of content and exposure research. Addiction 2017;112:28-50.

67 EFPIA. EFPIA report on ethics \& compliance activities, 2021. Available: https://www.efpia.eu/media/602865/efpia-code-report2020-20210629.pdf

68 European Commission. Communication from the Commission to the European Parliament, the Council, the European economic and social Committee and the Committee of the regions pharmaceutical strategy for Europe, 2020. Available: https://eur-lex.europa.eu/legalcontent/EN/TXT/?uri=CELEX:52020DC0761

69 IQVIA. Get to better business processes with embedded compliance, 2021. Available: https://www.iqvia.com/solutions/ integrated-global-compliance/commercial-compliance/ [Accessed 9 Jan 2021].
70 et alAnand R, Collier D, Jiang Y. Leveraging CMS open payments data to identify channel preferences and gather competitive intelligence, thereby improving HCP targeting ND. Available: https:// www.pmsa.org/jpmsa-vol05-article06

71 Ozieranski P, Csanádi M, Rickard E, et al. Under-reported relationship: a comparative study of pharmaceutical industry and patient organisation payment disclosures in the UK (2012-2016). BMJ Open 2020;10:e037351.

72 Rickard E, Ozieranski P, Mulinari S. Evaluating the transparency of pharmaceutical company disclosure of payments to patient organisations in the UK. Health Policy 2019;123:1244-50.

73 Department of Health and Human Services - Office of Inspector General. Open payments data: review of accuracy, precision, and consistency in reporting, 2018. Available: https://oig.hhs.gov/oei/ reports/oei-03-15-00220.pdf

74 Ministère des Solidarités et de la Santé. Discours d'Agnès Buzyn: remise du rapport sur l'amélioration de l'information des usagers et des professionnels de santé sur le médicament, 2018. Available: https://solidarites-sante.gouv.fr/actualites/presse/discours/article/ discours-d-agnes-buzyn-remise-du-rapport-sur-I-amelioration-de-Iinformation [Accessed 29 Oct 2021].

75 Ozaki A, Saito H, Senoo Y, et al. Overview and transparency of non-research payments to healthcare organizations and healthcare professionals from pharmaceutical companies in Japan: analysis of payment data in 2016. Health Policy 2020;124:727-35.

76 Greenway T, Ross JS. US drug marketing: how does promotion correspond with health value? BMJ;2017:j1855.

77 DeJong C, Aguilar T, Tseng C-W, et al. Pharmaceutical industrysponsored meals and physician prescribing patterns for Medicare beneficiaries. JAMA Intern Med 2016;176:1114-22.

78 Fleischman W, Agrawal S, King M, et al. Association between payments from manufacturers of pharmaceuticals to physicians and regional prescribing: cross sectional ecological study. BMJ 2016:354:i4189.

79 Mitchell AP, Trivedi NU, Gennarelli RL, et al. Are financial payments from the pharmaceutical Industry associated with physician prescribing?: A systematic review. Ann Intern Med 2021;174:353-61.

80 Nguyen TD, Bradford WD, Simon KI. Pharmaceutical payments to physicians may increase prescribing for opioids. Addiction 2019;114:1051-9.

81 Ozieranski P, Rickard E, Mulinari S. Exposing drug industry funding of UK patient organisations. BMJ 2019;365:11806.

82 Lexchin J, Fugh-Berman A. A ray of sunshine: transparency in physician-industry relationships is not enough. $J$ Gen Intern Med 2021;36:3194-8.

83 Parker L, Karanges EA, Bero L. Changes in the type and amount of spending disclosed by Australian pharmaceutical companies: an observational study. BMJ Open 2019;9:e024928.

84 Ganem-Chabenet D. Loi anti-cadeau: les Nouveautés Du Décret Du 15 Juin 2020 sur les Avantages Offerts aux Professionnels de Santé, 2020. Available: https://emservice.fr/ems/index.php/2020/09/10/ breve_dgc_septembre_2020/ [Accessed 19 Mar 2021].

85 CurrencyConverter. Currency converter 0.14.4, 2020. Available: https://pypi.org/project/CurrencyConverter/ [Accessed 19 Jan 2021]

86 FSA. Transparenzkodex, 2020. Available: https://www.fsa-pharma. $\mathrm{de} / \mathrm{de} /$ mitteilungen/presse/archiv/transparenzveroffentlichungen2019/

87 FARMAINDUSTRIA. Las compañías farmacéuticas dedicaron El año pasado 483 millones a actividades de investigación $Y$ formación científica Con organizaciones Y profesionales sanitarios, 2020. Available: https://www.farmaindustria.es/web/prensa/notas-deprensa/2020/06/26/las-companias-farmaceuticas-dedicaron-el-anopasado-483-millones-a-actividades-de-investigacion-y-formacioncientifica-con-organizaciones-y-profesionales-sanitarios/

88 Sciencelndustries. Disclosure obligation since 2016, 2020. Available: https://www.scienceindustries.ch/en/article/13958/disclosureobligation-since-2016

89 EFPIA. Report on ethics \& compliance activities, 2020. Available: https://www.efpia.eu/media/554639/efpia-code-report-2019.pdf

90 IPHA. Email communication, 2020.

91 ABPI. Disclosure UK, 2020. Available: https://www.abpi.org.uk/ourethics/disclosure-uk/ 